\title{
Investigation of Illumination Effects on the Electrical Properties of Au/ GO/p-InP Heterojunction with a Graphene Oxide Interlayer
}

\author{
Dasaradha Rao Lambada ${ }^{1} \cdot$ Shuming Yang ${ }^{1} \cdot$ Yiming Wang $^{1} \cdot$ Peirui $\mathrm{Ji}^{1} \cdot$ Shareen Shafique ${ }^{1} \cdot$ Fei Wang $^{1}$
}

Received: 30 May 2020 / Revised: 29 August 2020 / Accepted: 9 September 2020 / Published online: 4 November 2020

(c) The Author(s) 2020

\begin{abstract}
In this work, the electrical property of Au/graphene oxide/ $p$-InP hetero-structure has been evaluated by $I-V$ and $C-V$ measurements in dark and illuminated conditions (visible light). The diode exhibited significant rectifying behavior, thus indicating the heterojunction-type diode. The key electrical parameters of heterojunction diode including ideality factor $(n)$, series resistance $\left(R_{\mathrm{S}}\right)$, shunt resistance $\left(R_{\mathrm{sh}}\right)$, and barrier height $\left(\Phi_{\mathrm{b}}\right)$ are estimated from $I-V$ data based on the theory of thermionic emission. The modified Norde and Cheung's methods were utilized to evaluate the electrical parameters and compared the results. The current conduction mechanism at different voltage regions of $I-V$ has also been investigated. The variation of $1 / C^{2}$ versus voltage signifies linearity at high frequency $(1 \mathrm{MHz})$, indicating that the type of heterojunction can be abrupt. The experimental outcomes of this study revealed that the performance of heterojunction diode in dark is considerably good as compared to the illumination condition with respect to the lower values of $\Phi_{\mathrm{b}}, n, R_{\mathrm{s}}$, and interface state density $\left(\mathrm{N}_{\mathrm{ss}}\right)$.
\end{abstract}

Keywords Electrical properties · Heterojunction diode $\cdot$ Graphene oxide $\cdot I-V$ and $C-V$ techniques $\cdot$ Interface state density . Ideality factor

\section{Introduction}

Owing to the intriguing properties of III-V semiconductors, in particular, indium phosphide (InP) is a kind of prominent semiconductor material and extensively employed in the development of optoelectronic and microwave devices $[1,2]$. It has numerous applications including metal/insulator/semiconductor field effect transistors, photodetectors, solar cells, microwave sources, and amplifiers [3-7]. In addition, InP has great potential for radiation resistance in comparison to other semiconductor materials like GaAs [8] and $\mathrm{Si}$ [9], which makes it a promising candidate in telecommunication applications, especially optical generation, switching, and detection components. In the meantime, InPbased Schottky junctions suffer low Schottky barrier height, which will cause a huge leakage current and degenerate the performance of the devices resulting from the high surface state density and other nonstoichiometric defects [10]. The

Shuming Yang

shuming.yang@mail.xjtu.edu.cn

1 State Key Laboratory for Manufacturing System Engineering, Xi' an Jiaotong University, Xi' an 710049, China inserted layer of high conductive oxide material can act as a blockade of inter-diffusion, which can not only decrease the existing surface state density, leakage current, and series resistance, but also improve the shunt resistance and rectification ratio. Meanwhile, the inserted layer isolates metal from the semiconductor and hence hinders the inter-diffusion and reaction among them. Benefiting from these advantages, the metal/insulator/semiconductor (MIS) structure devices have emerged with excellent potential in a wide variety of applications, especially in optoelectronic and high-frequency devices owing to their easy and low-cost processing, better performance, flexibility, and low energy consumption. Therefore, in this regard, the in-depth knowledge of the rectification behavior characteristics of metal/insulator/InP structure would help to accelerate the development of the emerging potential applications.

There are only a few reported studies in open literature on the tuning of the Schottky barrier properties of metal/ bulk InP contact by inserting a very thin interfacial layer between the $\mathrm{M} / \mathrm{S}$ interface by different research groups [11-21]. Lin et al. [16] have prepared the $\mathrm{MoS}_{2} / p$-InP heterojunction diode by chemical vapor deposition. The $\mathrm{BH}$, ideality factor, and $R_{\mathrm{s}}$ values extracted from forward bias $J-V$ characteristics are $0.73 \mathrm{eV}, 2.4$, and $12.8 \Omega$ respectively. 
Chen et al. [17] reported the $\mathrm{Al} / \mathrm{MoO}_{3} / p$-InP MIS Schottky barrier diode and measured its electrical parameters with temperatures from 310 to $400 \mathrm{~K}$. Reddy et al. [18] demonstrated that effective improvement could be attributed to the modification of $\mathrm{Ti} / p$-type InP interface by inclusion of a polyvinylpyrrolidone (PVP) polymer interlayer. Recently, Acar et al. [21] fabricated the $\mathrm{Au} / \mathrm{ZnO} / p$-InP metal/oxide/ semiconductor structure by using RF magnetron sputtering technique, and they found the density of interface states of this structure is from $8.18 \times 10^{13}$ to $1.24 \times 10^{11} \mathrm{eV}^{-1} \mathrm{~cm}^{-2}$ with a change of frequency.

In recent years, an interesting layered material, graphene oxide (GO), has attracted many researchers' attention in a variety of applications due to its exceptional electrical, mechanical, and optical properties, which makes it one of the potential candidates in emerging electronics and optoelectronics. Currently, graphene/bulk semiconductor-based hybrid heterojunction has emerged in versatile diverse applications, such as solar cells, photodetectors, sensors, and Schottky junctions [22]. To date, many research groups have been devoted to constructing graphene-based hybrid heterostructures to modify or improve their performance with various bulk semiconductors such as GaAs [23], SiC [24, 25], AlGaN [26, 27], GaN [28-31], Ge [32, 33], and Si [34-39], whereas only a little work [40-42] had been reported on InP. Phan et al. [43] have explored the photoelectrical performance of Al/GO/n-Si/Al Schottky diode and revealed that the photocurrent increases while the light intensity increases, where the nanoscale GO film acts as a semiconductor with high photoconductivity. Kalita et al. [44] analyzed the photovoltaic properties of Au/pr-GO/n-Si Schottky diode in dark and illuminated conditions. The $J-V$ characteristics of the diode show good rectification and the leakage current is small under reverse bias in dark conditions. Yang et al. [45] have introduced a GO interlayer into $\mathrm{Gr} / \mathrm{Si}$ solar cells and found that the performance of $\mathrm{Gr} / \mathrm{GO} / \mathrm{Si}$ structure was significantly more stable than that without a GO interlayer, and the maximum power conversion efficiency with GO is about 6.18\%. Gullu et al. [42] prepared a Al/GO/n-InP heterojunction, where the MIS structure achieved higher barrier height $(0.85 \mathrm{eV})$ with $\mathrm{GO}$ of about $100 \%$ compared with the value $(0.43 \mathrm{eV})$ of the MS diode without a GO interlayer. However, there were no reports on heterojunction diode fabrication using graphene oxide (GO) Schottky contact on $p$-type InP with a detailed electrical characterization. Therefore, in this context, a thin graphene oxide film was used as an interlayer at the metal/semiconductor interface and the properties of the heterojunction were investigated under dark and illuminated conditions. It has been discovered that a thin inserted layer in the interface can be wiped out to enhance the interfacial properties and influence the quality and performance of the device. To validate the above arguments, we have fabricated the $\mathrm{Au} / \mathrm{GO} / p$-InP heterojunction and determined its electrical and photoelectrical properties. Moreover, the main electrical parameters under dark and illuminated conditions were also evaluated, compared, and discussed in detail.

\section{Experimental details}

A cleaned $p$-type (100) InP (Zn-doped, $0.5 \Omega \mathrm{cm}$ ) with 350$\mu \mathrm{m}$ thickness (given by the manufacturer) was taken for the fabrication of the device. First, the wafer was treated by trichloroethylene, acetone, and methanol with ultrasound. Then the degreased wafer was dipped in a mixture of $\mathrm{H}_{2} \mathrm{SO}_{4}$, $\mathrm{H}_{2} \mathrm{O}_{2}$, and $\mathrm{H}_{2} \mathrm{O}$ (5:1:1) for 1 min to clean the surface. After that, the wafer was treated with diluted HF $(10 \%)$ solution to etch the oxide layer. Subsequently, DI water was used to clean the wafers, which dried under the flow of high-purity $\mathrm{N}_{2}$ gas and then were immediately transferred into the deposition chamber. Pt film (30 nm, 99.99\%) was deposited by electron beam evaporation and annealed at $350{ }^{\circ} \mathrm{C}$ for $1 \mathrm{~min}$ in $\mathrm{N}_{2}$ atmosphere to attain good conductive contact. Initially, the graphene oxide powder (purchased from XF Nano) was dissolved in water for $12 \mathrm{~h}$ by ultrasonic agitation to achieve the homogeneous GO solution. Then, using the drop casting method, the GO layer was obtained on the front side of the substrate (see in Fig. 1a) and the sample was baked at $50{ }^{\circ} \mathrm{C}$. The thickness of GO was measured by a stylus profiler and the value was about $40 \mathrm{~nm}$, which was obtained from the difference between the average height of the upper surface and the average height of the lower surface, so no repeated measurements were made. The preparation process and the schematic illustration of $\mathrm{Au} / \mathrm{GO} / p$-InP heterojunction structure are given in Fig. 1a, b. In addition, AFM was adopted to evaluate the surface quality before and after depositing the GO layer and is depicted in Fig. 2. The images show the continuous GO film, which works as the interlayer between the metal and the semiconductor. Eventually, Au circular dots with $30 \pm 1 \mathrm{~nm}$ thickness and $0.7 \pm 0.0075 \mathrm{~mm}$ diameter were deposited through a stainless-steel mask.

The $I-V$ and $C-V$ data of $\mathrm{Au} / \mathrm{GO} / p-\mathrm{InP}$ heterojunction were recorded by semiconductor device analyzer (Keysight B1500A) in dark and illuminated conditions. The illumination was carried out by a general commercial lamp with a power density of $30 \mathrm{~mW} / \mathrm{cm}^{2}$. As well, the capacitance frequency $(C-f)$ characteristics were also evaluated using a Keysight B1500A device. In addition, SEM was also used to evaluate the surface of the $\mathrm{GO} / p$-InP structure as depicted in Fig. 2c.

\section{Results and discussion}

The $I-V$ behavior of the $\mathrm{Au} / \mathrm{GO} / p$-InP heterojunction is measured in dark and illuminated conditions, respectively. As shown in Fig. 3, the Au/GO/p-InP heterojunction has exhibited a good rectifying behavior, 
Fig. 1 a Schematic step-by-step preparation process of the $\mathrm{Au} /$ $\mathrm{GO} / p$-InP heterojunction structure. b Schematic illustration of $\mathrm{Au} / \mathrm{GO} / p-\mathrm{InP}$ heterojunction diode (a)
Graphene 0xide
$\mathrm{Au}$
InP
$\mathrm{Pt}$

Cleaning InP substrate

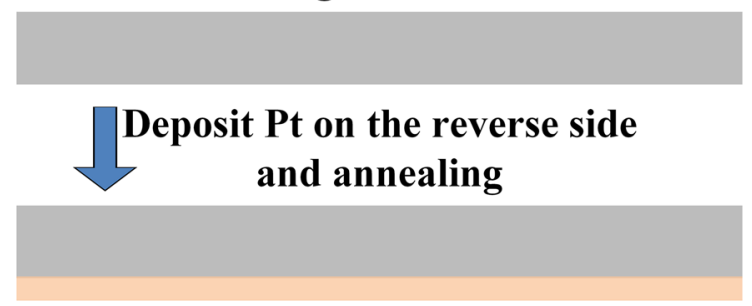

Deposit GO on the obverse side

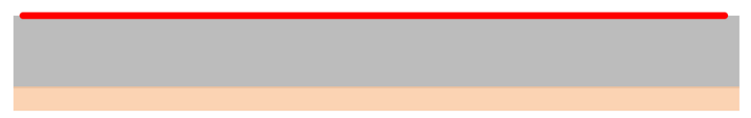

Deposit Au dots on GO film

(b)

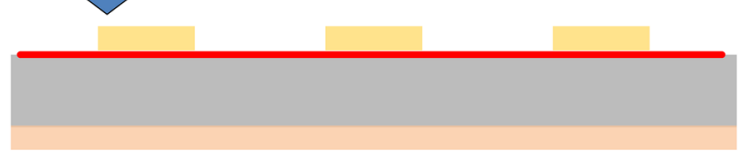

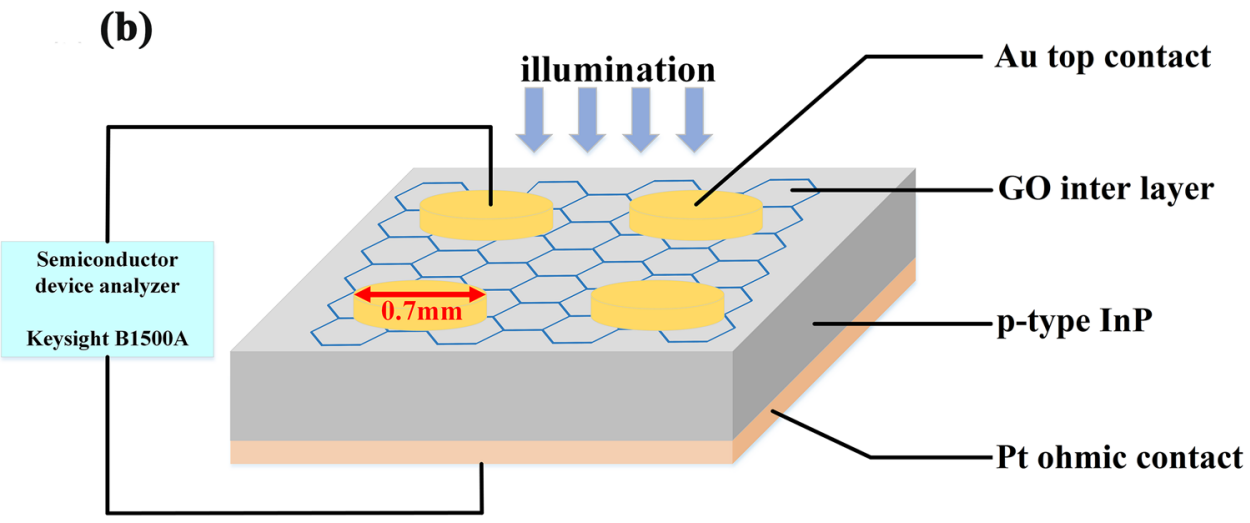

while the ratios of the forward current and reverse current $\left(I_{\mathrm{F}} / I_{\mathrm{R}}\right)$ in dark and illuminated conditions are $(9.66 \pm 0.01) \times 10^{-2}$ and $(5.14 \pm 0.01) \times 10^{-3}$ at $3 \mathrm{~V}$, respectively. The measured reverse leakage currents are found to be $(5.6812 \pm 0.0001) \times 10^{-8} \mathrm{~A}$ at $1 \mathrm{~V}$ in the dark and $(4.1393 \pm 0.0001) \times 10^{-7} \mathrm{~A}$ at $1 \mathrm{~V}$ under illuminated conditions, respectively. Based on the TE theory, the current is [46],

$I=I_{0} \exp \left(\frac{q\left(V-I R_{S}\right)}{n k_{B} T}\right)\left[1-\exp \left(\frac{-q\left(V-I R_{S}\right)}{k_{B} T}\right)\right]$

where $V$ is voltage, $I R_{\mathrm{S}}$ is the voltage drop across the $R_{\mathrm{S}}, k_{\mathrm{B}}$ is Boltzmann's constant $\left(1.3806 \times 10^{-23} \mathrm{~J} / \mathrm{K}\right), T$ is absolute temperature in Kelvin, $q$ is the charge of electron $\left(1.602 \times 10^{-19} \mathrm{C}\right)$, and $I_{\mathrm{o}}$ is the saturation current.
$I_{0}=A A^{*} T^{2} \exp \left[\left(-q \Phi_{b}\right) /\left(k_{B} T\right)\right]$

where $A$ is active area, $A *$ is effective Richardson constant for $p$-InP $\left(60 \mathrm{~A} \mathrm{~cm}^{-2} \mathrm{~K}^{-2}\right), \Phi_{\mathrm{b}}$ is Schottky barrier height. From Eqs. (1) and (2), the ideality factor and barrier height can be rearranged as

$n=\frac{q}{k T}\left[\frac{\mathrm{d}\left(V-I R_{S}\right)}{\mathrm{d}(\ln I)}\right]$

and

$\Phi_{b}=(k T / q) \ln \left(A^{*} A T^{2} / I_{0}\right)$ 
$2.3 \mathrm{~nm}$

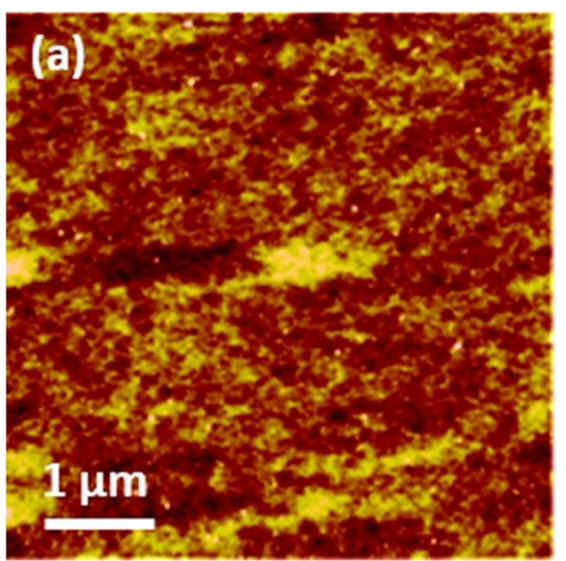

$99.3 \mathrm{~nm}$
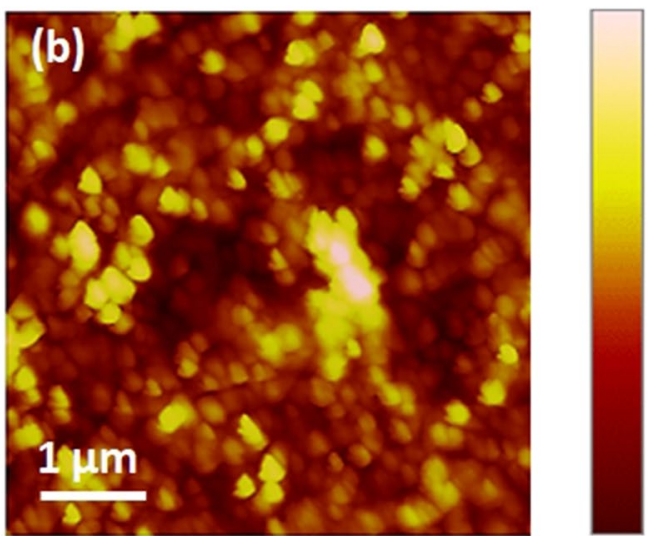

$-78.2 \mathrm{~nm}$

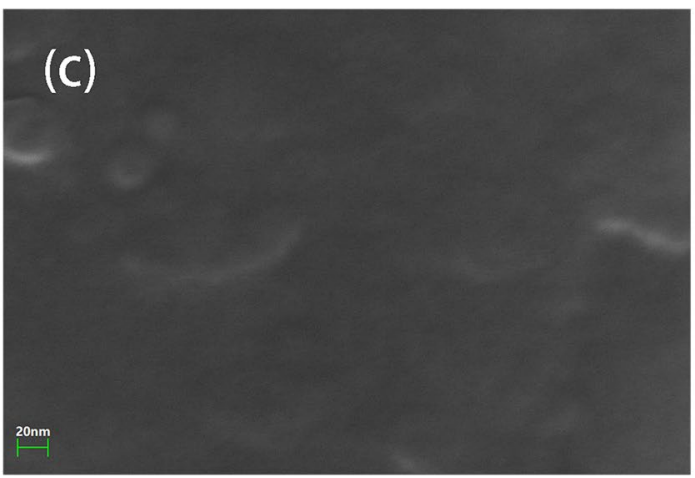

Fig. 2 Atomic force microscopy images of a the etched surface of $p$-InP, $\mathbf{b}$ surface of the GO thin film on $p$-InP, and $\mathbf{c}$ SEM image of the etched surface of $p$-InP

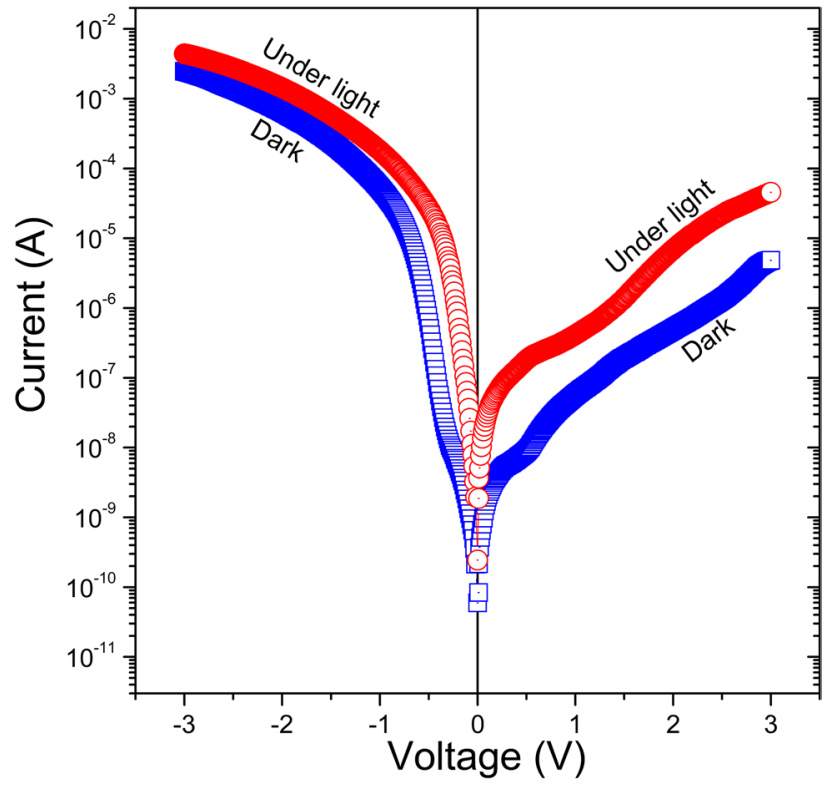

Fig. 3 The forward and reverse bias $(I-V)$ characteristics of $\mathrm{Au} /$ $\mathrm{GO} / p$-InP heterojunction measured at room temperature in dark and under illumination conditions
To investigate, the $V<3 k T$ regime, in dark and under illumination, the saturation current $\left(I_{\mathrm{o}}\right)$ is derived from semilog reverse-bias $I-V$ plots as shown in Fig. 4. Using Eq. (2), very small saturation current $\left(I_{\mathrm{o}}\right)$ values of $5.94 \times 10^{-11} \mathrm{~A}$ and $2.44 \times 10^{-10} \mathrm{~A}$ can be acquired in dark and under illumination, respectively. The barrier heights of $\mathrm{Au} / \mathrm{GO} / p$ - $\mathrm{InP}$ heterojunction could be obtained through the saturation current density $\left(I_{\mathrm{o}}\right)$ in dark and under illumination. The ideality factor and barrier height of the $\mathrm{Au} / \mathrm{GO} / p$-InP heterojunction are estimated to be 1.67 and $0.87 \mathrm{eV}$ in the dark and 1.81 and $0.83 \mathrm{eV}$ in light conditions at room temperature, respectively. A summary of these experimental results is provided in Table 1. It can be observed that the differences in $\Phi_{\mathrm{b}}$ obtained in dark and illuminated conditions were due to the device illumination at $30 \mathrm{~mW} / \mathrm{cm}^{2}$ light and extra free charge carriers (electron-hole pairs) occurred in the devices. Now, these carrier movements cause an increase in the current in the reverse region depending on the illumination [47]. Usually, the expected value of the ideal factor should be close to unity, but as seen from Table 1, the obtained ideality factor is greater than 1, thus exhibiting the deviations from the ideal 

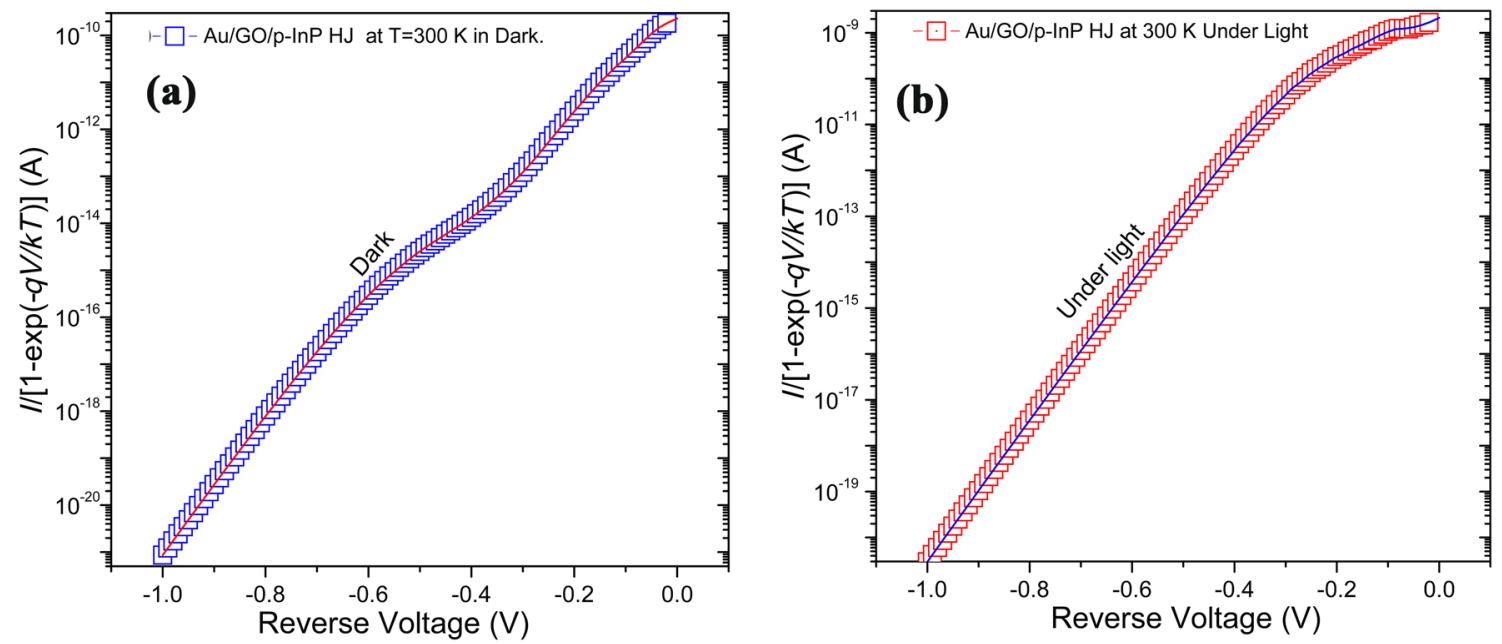

Fig. 4 Plots of semi-logarithmic $I /[1-\exp (-q V / k T)$ versus voltage $(\mathrm{V})$ for the Au/GO/p-InP heterojunction a in the dark and $\mathbf{b}$ under illumination conditions from the reverse bias $I-V$ data at room temperature

Table 1 The measured barrier height, ideality factor, series resistance, and interface state density values of dark and illumination conditions of the $\mathrm{Au} /$ graphene oxide (GO)/p-InP heterojunction diode

\begin{tabular}{|c|c|c|}
\hline Parameter & Under dark conditions & Under light (visible) conditions \\
\hline \multicolumn{3}{|l|}{ From $I-V$ characteristics } \\
\hline Barrier height, $\Phi_{\mathrm{b}}(\mathrm{eV})$ & 0.87 & 0.83 \\
\hline Ideality factor, $n$ & 1.67 & 1.81 \\
\hline Leakage current (A) at $1 \mathrm{~V}$ & $5.6812 \times 10^{-8}$ & $4.1392 \times 10^{-7}$ \\
\hline Saturation current (A) at $0 \mathrm{~V}$ & $5.9430 \times 10^{-11}$ & $2.4412 \times 10^{-10}$ \\
\hline Series resistance, $R_{\mathrm{S}}(\Omega)$ & 1209 & 680 \\
\hline Shunt resistance $R_{\mathrm{sh}}(\mathrm{M} \Omega)$ & 120 & 10 \\
\hline \multicolumn{3}{|l|}{$\begin{array}{l}\text { From Cheung's method } \\
\mathrm{d} V / \mathrm{d}(\ln I) \text { versus } I\end{array}$} \\
\hline Series resistance, $R_{\mathrm{S}}(\Omega)$ & 367.560 & 268.701 \\
\hline Ideality factor, $\mathrm{n}$ & 1.86 & 1.97 \\
\hline \multicolumn{3}{|l|}{$H(I)$ versus $I$} \\
\hline Series resistance, $R_{\mathrm{S}}(\Omega)$ & 828.996 & 599.525 \\
\hline Barrier height, $\Phi_{\mathrm{b}}(\mathrm{eV})$ & 0.93 & 0.84 \\
\hline \multicolumn{3}{|l|}{ From Norde's method } \\
\hline Barrier height, $\Phi_{\mathrm{b}}(\mathrm{eV})$ & 0.88 & 0.84 \\
\hline Series resistance, $R_{\mathrm{S}}(\mathrm{k} \Omega)$ & 2572 & 1.457 \\
\hline \multicolumn{3}{|l|}{ From $C-V$ characteristics } \\
\hline Diffusion potential $V_{\mathrm{do}}(\mathrm{V})$ & 0.98 & 0.86 \\
\hline Barrier height, $\Phi_{\mathrm{b}}(\mathrm{eV})$ & 1.01 & 0.88 \\
\hline \multicolumn{3}{|l|}{ Surface potential } \\
\hline Barrier height (eV) & 0.83 & 0.76 \\
\hline Ideality factor $(n)$ & 1.82 & 1.78 \\
\hline \multicolumn{3}{|l|}{ Interface state density $\left(N_{\mathrm{SS}}\right)$} \\
\hline$\left(\mathrm{eV}^{-1} \mathrm{~cm}^{-2}\right)$ & $\begin{array}{c}3.3629 \times 10^{16}\left(0.39 \mathrm{eV}-E_{\mathrm{v}}\right) \text { to } \\
4.0248 \times 10^{15}\left(0.77 \mathrm{eV}-E_{\mathrm{v}}\right)\end{array}$ & $\begin{array}{c}3.6584 \times 10^{16}\left(0.41 \mathrm{eV}-E_{\mathrm{v}}\right) \text { to } \\
2.9443 \times 10^{15}\left(0.84 \mathrm{eV}-E_{\mathrm{v}}\right)\end{array}$ \\
\hline
\end{tabular}

contact. This may origin from various factors, like different fitting procedures for data analysis, leakage current, series resistance, interface states, as well as the tunneling process [48-51].
Normally, an ideal Schottky diode exhibits low series resistance $\left(R_{\mathrm{S}}\right)$ that allows high current through the device, and large shunt resistance $\left(R_{\mathrm{sh}}\right)$ for small leakage current [46], which has affected the $\log I-V$ characteristics of the 
diode. In order to evaluate the value of $R_{\mathrm{s}}$ and $R_{\mathrm{sh}}$, a plot of junction resistance $\left(R_{\mathrm{j}}\right)$ of the $\mathrm{Au} / \mathrm{GO} / p$-InP heterojunction diode was potted in Fig. 5 . The estimated $R_{\mathrm{s}}$ and $R_{\mathrm{sh}}$ are $1209 \Omega$ and $120 \mathrm{M} \Omega$ under darkness, $680 \Omega$ and $10 \mathrm{M} \Omega$ under illumination, respectively. As shown in Table 1, the $\mathrm{Au} / \mathrm{GO} / p-\mathrm{InP}$ heterostructure has low $R_{\mathrm{s}}$ and high $R_{\mathrm{sh}}$, thus indicating that the heterojunction is structure suitable for the potential applications.

As a result of the combined effects, the $\log (I)-V$ plots of $\mathrm{Au} / \mathrm{GO} / p$-InP heterojunction deviate at high currents (as shown in Fig. 3). In this context, the estimated value of $R_{\mathrm{s}}$, $\Phi_{\mathrm{b}}$ and $n$ can be deduced using the well-known Cheung's functions [52] as below:

$\mathrm{d} V / \mathrm{d}(\ln I)=I R_{S}+n\left(k_{B} T / q\right)$

$H(I)=V-n\left(k_{B} T / q\right) \ln \left[I /\left(A A^{*} T^{2}\right)\right]$

and $H(I)$ is given by

$H(I)=I R_{S}+n \Phi_{b}$

Figure 6 describes $\mathrm{d} V / \mathrm{d}(\ln I)$ and $H(I)$ of the heterojunction in the dark and under illumination, respectively. Using the linear regression line of $\mathrm{d} V / \mathrm{d}(\ln I)-I$ plot, the parameters $R_{\mathrm{S}}$ and $n k T / q$ can be deduced from the slope and intercept, respectively. From $\mathrm{d} V / \mathrm{d}(\ln I)-V$ plot, $R_{\mathrm{s}}$ and $n$ were found to be $367 \Omega$ and 1.86 in the dark, $268 \Omega$ and 1.97 under illuminated condition, respectively. From $H(I)-V$ plot, the $R_{\mathrm{s}}$ and $\Phi_{\mathrm{b}}$ values are estimated to be $829 \Omega, 0.93 \mathrm{eV}$ in the dark and $599 \Omega, 0.84 \mathrm{eV}$ under illumination conditions respectively. The estimated values were also presented in Table 1 . The experimental results indicate that the $R_{\mathrm{S}}$ values attained by the two equations are well in concurrence with each other,

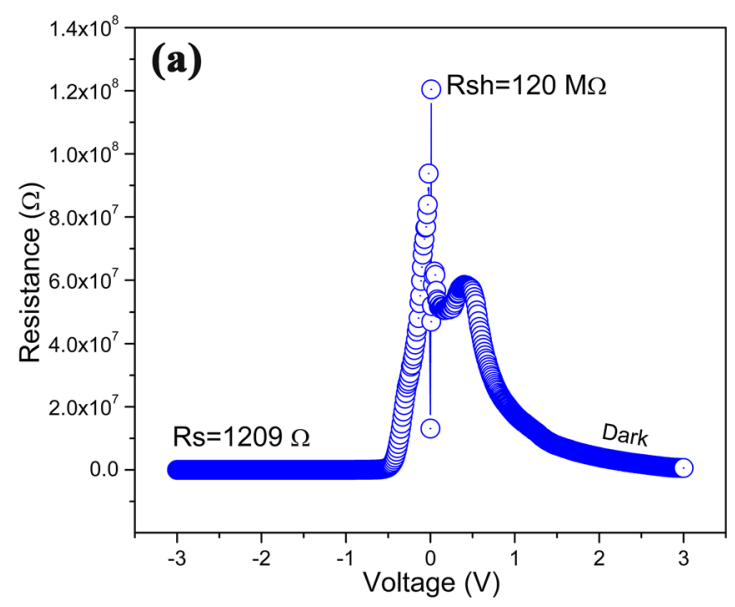

conforming their consistency and validity. It is also observed from Table 1 , that the $\Phi_{\mathrm{b}}$ and $n$ deviate considerably with those results from the $\log (I)-V$ measurement. This deviation is due to the employed methods to estimate the $\Phi_{\mathrm{b}}$ and $\mathrm{n}$ in various regions of $\log (I)-V$ data.

A well-known modified Norde method was also utilized to evaluate $\mathrm{Au} / \mathrm{GO} / p$-InP heterojunction diode for the comparison. From this method, the values of $\Phi_{\mathrm{b}}$ and $R_{\mathrm{s}}$ are estimated from $\log (I)-V$ data using modified Norde method [53] as given below:

$F(V)=V / \gamma-\left(k_{B} T / q\right) \ln \left[I(V) /\left(A A^{*} T^{2}\right)\right]$

where $\gamma$ is a (dimensionless) integer greater than the ideality factor $(n)$, and $I(V)$ is the current obtained from the $\log (I)-V$ curve. $F(V)-V$ is plotted using Eq. (8) for the $\mathrm{Au} / \mathrm{GO} / p$-InP heterojunction as shown in Fig. 7a and b. The effective $\Phi_{\mathrm{b}}$ can be derived by:

$\Phi_{b}=F\left(V_{\min }\right)+V_{\min } / 2-k_{B} T / q$

where $F\left(V_{\min }\right)$ is the minimum value of $F(V)$ corresponding to the minimum voltage $V_{\min }$, which are attained from the $F(V)-V$ plot (Fig. 7). Similarly, the series resistance $R_{\mathrm{S}}$ is obtained by using the following equation:

$R_{s}=\left[k_{B} T(r-n)\right] /\left(q I_{\min }\right)$

where $n$ is the ideality factor, $I_{\min }$ is the current minimum corresponding to the minimum point of $F\left(V_{\min }\right)$, the estimated values of $R_{\mathrm{s}}$ and $\Phi_{\mathrm{b}}$ are $2572 \mathrm{k} \Omega, 0.88 \mathrm{eV}$ in dark, and $1.457 \mathrm{k} \Omega, 0.84 \mathrm{eV}$ under illumination for the $\mathrm{Au} / \mathrm{GO} / p$ InP heterojunction diode, respectively. These results clearly confirm the similarity of the barrier height $\left(\Phi_{\mathrm{b}}\right)$ values obtained from Cheung's and Norde methods, as well as high

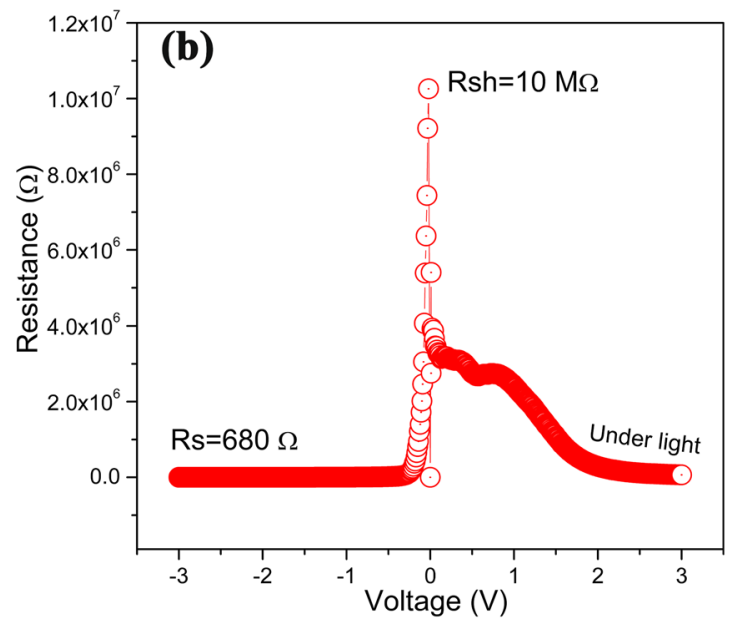

Fig. 5 The plots of junction resistance $R_{j}$ versus $\mathrm{V}$ for the $\mathrm{Au} / \mathrm{GO} / p$-InP heterojunction calculated from $I-V$ data $\mathbf{a}$ in the dark $\mathbf{b}$ under illumination conditions at room temperature 

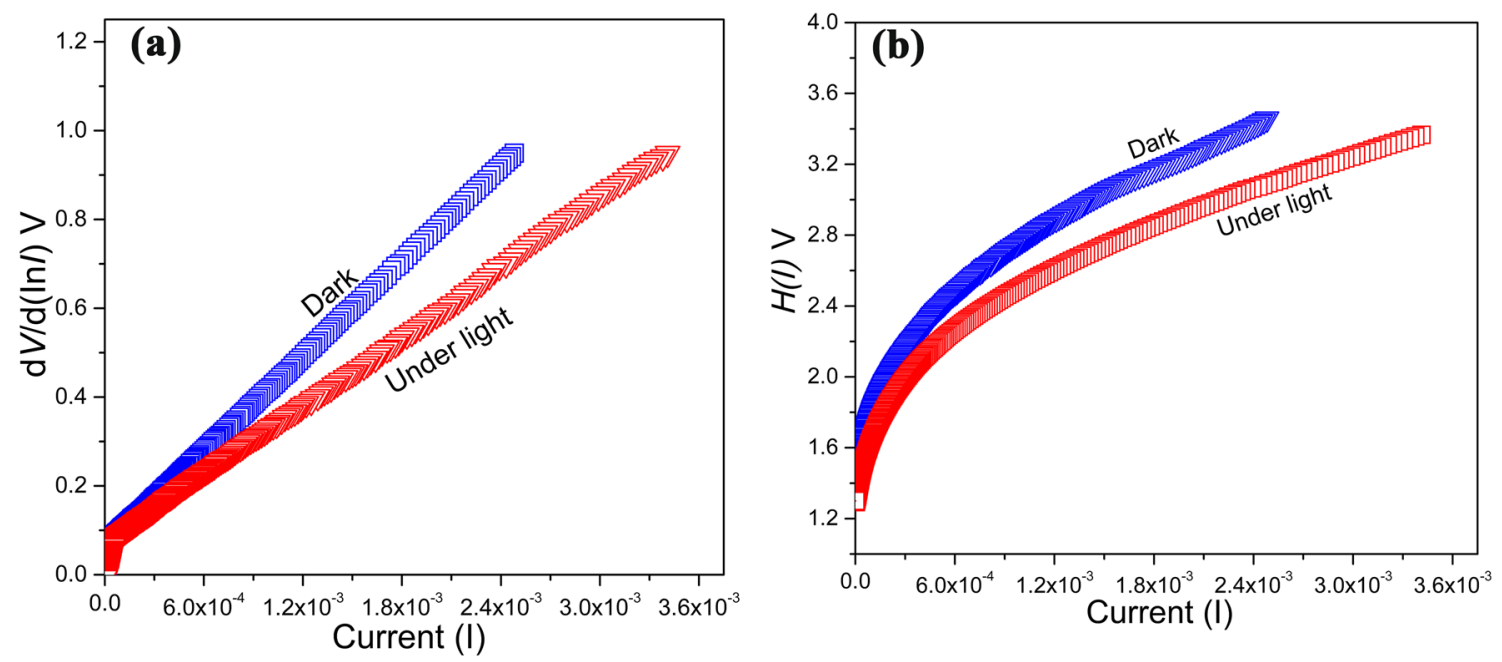

Fig. 6 Experimental plots of a $\mathrm{d} V / \mathrm{d}(\ln I)$ versus $\mathrm{I}$, b $H(I)$ versus $I$ of the $\mathrm{Au} / \mathrm{GO} / p$-InP heterojunction in dark and under illumination condition at room temperature
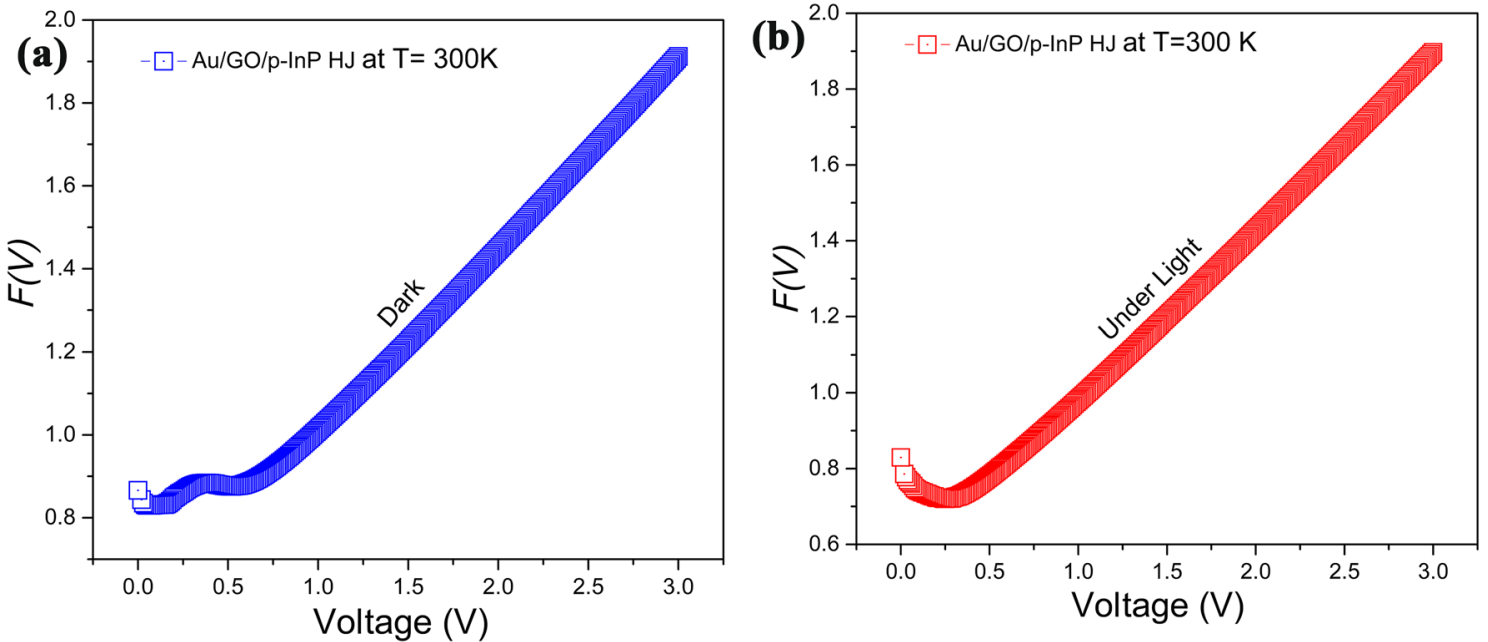

Fig. $7 F(V)$ versus $V$ plots for the $\mathrm{Au} / \mathrm{GO} / p$-InP heterojunction a in the dark, $\mathbf{b}$ under illumination condition at room temperature

reliability and efficiency of these techniques. Meanwhile, $R_{\mathrm{s}}$ values obtained from the two methods have some discrepancy, because different regions of $\log (I)-V$ data were used in these applied methods. The estimated values of $\Phi_{\mathrm{b}}$ and $R_{\mathrm{S}}$ are given in Table 1.

In general, considering the native oxide layer, the current through the Schottky junction can be estimated by [3].

$I=A A^{*} T^{2} \exp \left(\left(-q \Psi_{\text {surf }}\right) /(k T)\right) \exp \left(\left(-q V_{n}\right) /(n k T)\right)$

Besides, if surface potential $\Psi_{\text {surf }}\left(I_{\mathrm{c}}, V_{\mathrm{c}}\right), V_{\mathrm{c}}$ are known and $n=1 / \alpha$, the barrier heights $\Phi_{\mathrm{b}}$ can be obtained [54]. According to Chattopadhyay's method [54], from Eq. (11), the surface potential $\left(\Psi_{\text {surf }}\right)$ can be described as
$\Psi_{\text {surf }}=(k T / q) \ln \left(\left(A A^{*} T^{2}\right) / I\right)-V_{n}$

where $V_{\mathrm{n}}$ is the potential difference of Fermi level and valence band maximum, given as $V_{\mathrm{n}}=k T / q \ln \left(N_{\mathrm{V}} / N_{\mathrm{A}}\right)$. $N_{\mathrm{A}}$ is the accepter carrier concentration $\left(N_{\mathrm{A}}=2\left(2 \Pi m^{*} k T / h^{2}\right)^{3 / 2}\right.$ with $m^{*}=0.078 m_{\mathrm{o}}$, while $m_{\mathrm{o}}$ is electron effective mass and $N_{\mathrm{v}}$ is the effective density of states in $p$-InP valence band [55]. Thus, surface potential $\Psi_{\text {surf }}$ is deduced by substituting the $V_{\mathrm{n}}$ value in Eq (12). Figure 8 depicts the experimental surface potential $\Psi_{\text {surf }}$ of the $\mathrm{Au} / \mathrm{GO} / p$-InP heterojunction diode. From the plot, the values of $\mathrm{n}$ and $\Phi_{\mathrm{b}}$ can be evaluated by the relation $\Phi_{\mathrm{b}}=\Psi_{\text {surf }}\left(I_{\mathrm{c}}, V_{\mathrm{c}}\right)+\alpha V_{\mathrm{c}}+V_{\mathrm{n}}[54,56]$. The value of $\alpha$ is 
$-\alpha=\left(\mathrm{d} \Psi_{\text {surf }} / \mathrm{d} V\right)_{I_{\mathrm{C}} V_{\mathrm{c}}}$

As shown in Fig. 8, the critical value of $V_{\mathrm{c}}$ and $\Psi_{\text {surf }}\left(I_{\mathrm{c}}\right.$, $V_{\mathrm{c}}$ ) for the heterojunction are calculated. The $\Phi_{\mathrm{b}}$ and $n$ are calculated using Eqs. (12) and (13) and the values are $0.83 \mathrm{eV}, 1.82$ in the dark and $0.76 \mathrm{eV}, 1.78$ under the illumination conditions, respectively.

The $C-V$ measurement is one of the useful tools to attain the key information about the depletion region of the device structure. The characterization of the heterojunction under $1 \mathrm{kHz} \sim 1 \mathrm{MHz}$ is described in Fig. 9. It can be clearly observed that the measured capacitance is an intrinsic function of both applied bias and frequency. However, Fig. 9 shows that the capacitance of the $\mathrm{Au} / \mathrm{GO} / p$-InP heterojunction exhibits a slow decline with frequency increment, i.e., it offers higher capacitance at low frequencies $(f=1-10 \mathrm{kHz})$ and lower capacitance at high frequencies $(f=100 \mathrm{kHz}$ to $1 \mathrm{MHz}$ ). This predicated that the interface states have an influence on the variance between the capacitance measured at different frequencies [57].

Additionally, parameters like doping (accepter) concentration $\left(N_{\mathrm{A}}\right)$, diffusion potential $\left(V_{\mathrm{do}}\right)$, and barrier height $\Phi_{\mathrm{b}}(C-V)$ of $\mathrm{Au} / \mathrm{GO} / p$-InP heterojunction were evaluated by $C-V$ method. The depletion capacitance of $\mathrm{Au} / \mathrm{GO} / p-\mathrm{InP}$ heterojunction is expressed as: $[3,46]$.

$1 / C^{2}=2\left(V_{\mathrm{do}}+V\right) /\left(q \varepsilon_{s} A^{2} N_{A}\right)$

where $A$ is the active area, $\varepsilon_{\mathrm{s}}$ is the permittivity $\left(\varepsilon_{\mathrm{p}-\mathrm{InP}}=12.4 \varepsilon_{\mathrm{o}}\right)$. The plot of $1 / C^{2}-V$ measured at a high frequency of $1 \mathrm{MHz}$ in dark and illuminated condition is shown in Fig. 10. The $1 / C^{2}-V$ curves should be yielded a straight

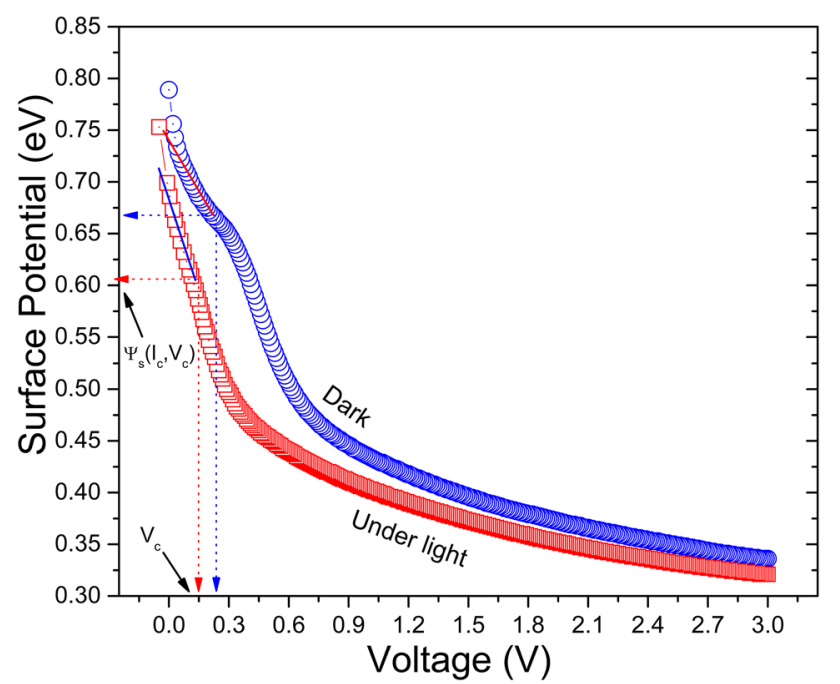

Fig. 8 Plots of surface potential $\left(\Psi_{\text {surf }}\right)$ versus forward voltage $(V)$ of the $\mathrm{Au} / \mathrm{GO} / p-\mathrm{InP}$ heterojunction at room temperature in the dark and under illumination conditions

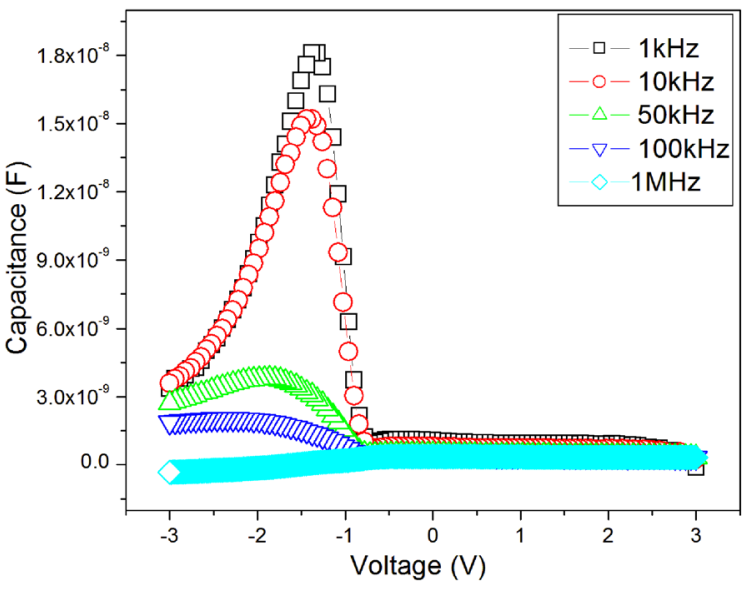

Fig. 9 The forward and reverse bias voltage $C-V$ characteristics of the $\mathrm{Au} / \mathrm{GO} / p$-InP heterojunction measured with different frequencies $(1 \mathrm{kHz}$ to $1 \mathrm{MHz})$ at room temperature

line [55]. From $1 / C^{2}-V$ plot, $N_{\mathrm{A}}, V_{\mathrm{do}}$, and $\Phi_{\mathrm{b}}(C-V)$ of the heterojunction are found to be $4.44 \times 10^{18} \mathrm{~cm}^{-3}, 0.98 \mathrm{~V}$ and $1.01 \mathrm{eV}$ in dark, and $3.23 \times 10^{18} \mathrm{~cm}^{-3}, 0.86 \mathrm{~V}$ and $0.88 \mathrm{eV}$ under illumination, respectively. $\mathrm{N}_{\mathrm{A}}$ and $\mathrm{V}_{\mathrm{do}}$ are showing lower values under the illumination condition whereas the same for the dark condition exhibit higher values. The decrease in diffusion potential and the increase in the activation carrier concentration under illumination condition implies an enhancement in the heterojunction performance and exhibits a good control for the optoelectronic applications. Although the $\Phi_{\mathrm{b}}$ estimated from $C-V$ data offers higher values than their counterparts derived from $I-V$ data, which could be attributed to the different nature of $I-V$ and $C-V$ measurement techniques [57-60].

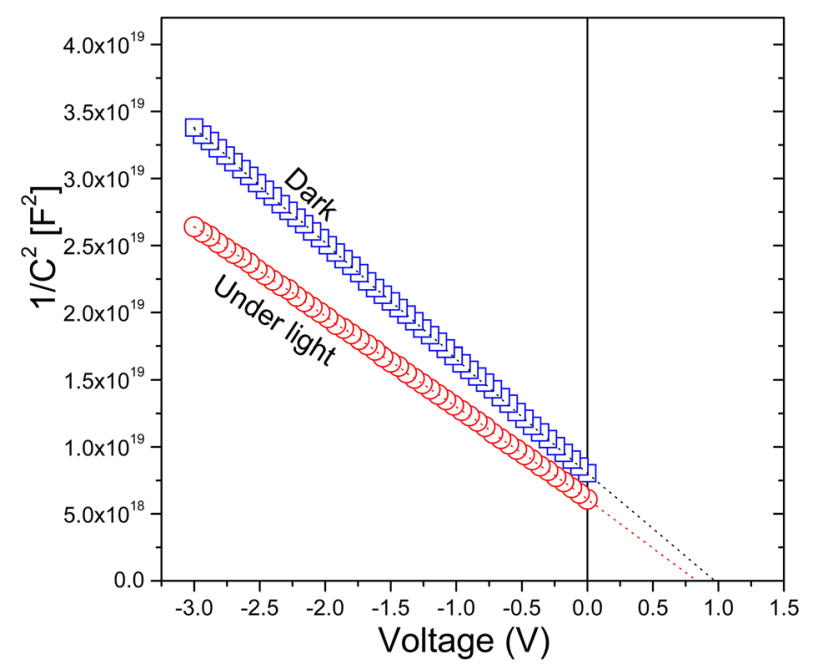

Fig. 10 The experimental $1 / C^{2}$ versus $V$ plots of the $\mathrm{Au} / \mathrm{GO} / p$-InP heterojunction at room temperature in the dark and under illumination condition 
Further, the interface state density $\left(N_{\mathrm{ss}}\right)$ is a very prominent parameter in the diode which has a strong impact on the conducting organic/inorganic InP interface. In $n$ case of an adequately thicker interfacial layer, the effective barrier height $\left(\Phi_{\mathrm{e}}\right)$ and $N_{\mathrm{ss}}$ at the interface are stated below:

$\Phi_{e}=\Phi_{b}+\left(\mathrm{d} \Phi_{e} / \mathrm{d} V\right) V=\Phi_{e}+\beta V$

where $\beta$ is the voltage coefficient. According to Card and Rhoderick [61, 62], $N_{\mathrm{ss}}$ versus $E_{\mathrm{ss}}-E_{\mathrm{v}}$ for $p$-type semiconductor barrier diode can be given as the following relation

$N_{s s}=\left(\varepsilon_{i} / \delta q\right)(n(V)-1)-\varepsilon_{s} /\left(q w_{d}\right)$

and

$n(V)=1+\left(\delta / \mathcal{E}_{i}\right)\left(\mathcal{E}_{s} / W_{d}+q N_{s s}\right)$

where $\varepsilon_{\mathrm{s}}=12.4 \varepsilon_{\mathrm{o}}$ and $\varepsilon_{\mathrm{i}}=3.8 \varepsilon_{\mathrm{o}}$ are the permittivity of semiconductor and interfacial layer, respectively. $\delta$ is interfacial layer thickness, $N_{\mathrm{ss}}$ is interface state density and $W_{\mathrm{D}}$ is depletion layer width which is estimated by $1 / C^{2}-V$ plot at $1 \mathrm{MHz}$. The energy $\left(E_{\mathrm{ss}}\right)$ distribution of $N_{\mathrm{ss}}$ with respect to valence band top edge $\left(E_{\mathrm{V}}\right)$ at semiconductor surface is presented as below

$E_{\mathrm{ss}}-E_{\mathrm{V}}=\left(\Phi_{\mathrm{e}}-V\right) q$

where $V$ is a voltage drop across the depletion layer. Thus, the $N_{\text {ss }}$ can be calculated using Eq. (16) combined with Eqs. (15) and (18). The values of $N_{\mathrm{ss}}$ exponentially decays with an increase in $E_{\mathrm{ss}}-E_{\mathrm{v}}$ for heterojunction in the dark and under the illumination conditions is nicely described through Fig. 11. Also, in Fig. 11, a prominent enhancement of $N_{\text {ss }}$ has been observed at the middle of the forbidden energy band gap to valence band maximum. As observed in Fig. $11, N_{\mathrm{ss}}$ varied in the range of $3.3629 \times 10^{16} \mathrm{eV}^{-1} \mathrm{~cm}^{-2}$ in $\left(0.39 \mathrm{eV}-\mathrm{E}_{\mathrm{v}}\right)$ to $4.0248 \times 10^{15} \mathrm{eV}^{-1} \mathrm{~cm}^{-2}$ in $\left(0.77 \mathrm{eV}-\mathrm{E}_{\mathrm{v}}\right)$ in the dark, and $3.6584 \times 10^{16} \mathrm{eV}^{-1} \mathrm{~cm}^{-2}$ in $\left(0.41 \mathrm{eV}-\mathrm{E}_{\mathrm{v}}\right)$ $\mathrm{eV}$ to $2.9443 \times 10^{15} \mathrm{eV}^{-1} \mathrm{~cm}^{-2}$ in $\left(0.84 \mathrm{eV}-\mathrm{E}_{\mathrm{v}}\right)$ under the illumination condition, respectively, for the $\mathrm{Au} / \mathrm{GO} / p-\mathrm{InP}$ heterojunction diode. A monotonic increase in $N_{\text {ss }}$ with respect to voltage lowering is clearly observable. This type of behavior of interface states $\left(N_{\mathrm{ss}}\right)$ can be elucidated by charge and discharge of $N_{\mathrm{ss}}$ under illumination impact [63].

At the same time, to explore the predominant current transport mechanism of $\mathrm{Au} / \mathrm{GO} / p-\mathrm{InP}$ heterojunction, a $\log -\log I-V$ plot is depicted in Fig. 12. The plot can be sub-divided into three distinct regions (namely as region I, II, III) based on bias voltage. At region $I$ (lower forward voltage $\mathrm{V}<0.08 \mathrm{~V}$ ), a linear dependency of the current on the applied bias $(I \sim V)$ is observed, indicating the transport mechanism obeys the Ohm's law (ohmic-type behavior) [64]. At region II (moderately high voltage, i.e., $0.15 \mathrm{~V}<V<0.40 \mathrm{~V}$ ), the exponential increment of current $(I \sim \exp (\alpha V))$ suggests that the charge conduction

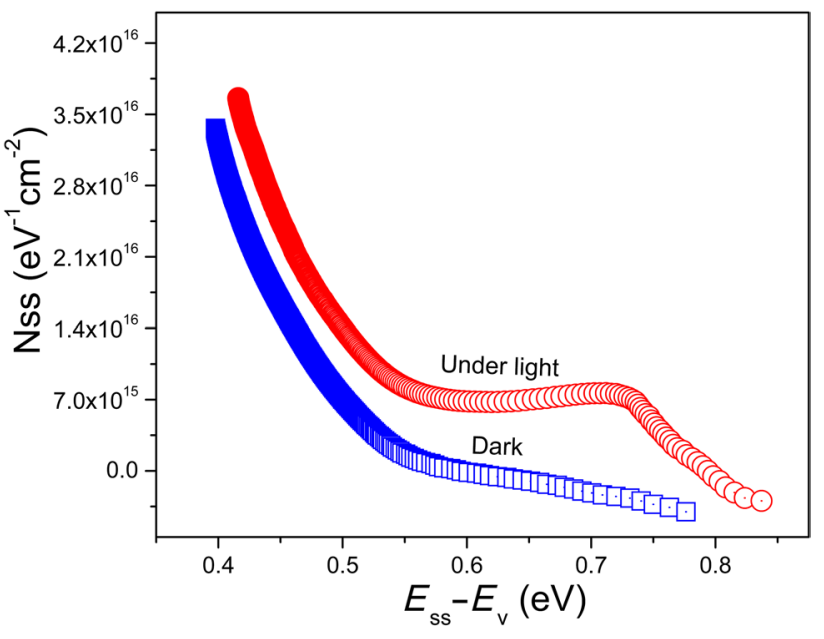

Fig. 11 Energy density distribution of the surface states obtained from forward bias $I-V$ data for $\mathrm{Au} / \mathrm{GO} / p$-InP heterojunction in dark and under illumination conditions at room temperature

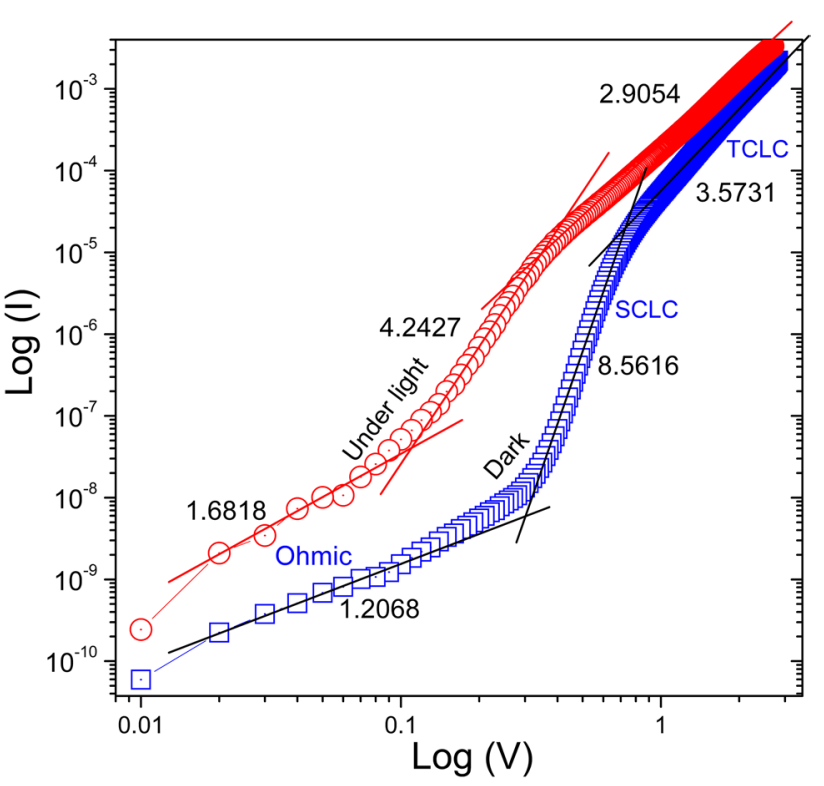

Fig. 12 The forward bias $\log (I)$ versus $\log (V)$ plots of the $\mathrm{Au} / \mathrm{GO} / p$ InP heterojunction diode at room temperature in dark and under illumination conditions

mechanism is dominated by the space-charge-limited current (SCLC) with a discrete trapping level [65]. Eventually, in the region III (at high-voltage region, i.e., $0.80 \mathrm{~V}<V<2.30 \mathrm{~V}$ ), the slope of the plot is inclined to decrease because the device approaches towards the trap-filling limit [66]. The term 'trapsfilling' significantly influences the conduction process of semiconductors. The experimental outcomes revealed that the studied heterostructure exhibits a clear diversion from ohmictype of conduction at lower voltage range (region I) to SCLC at higher voltage range (regions II and III) under dark and 
illuminated conditions, respectively. This behavior is in good agreement with published reports by various research groups working on different organic hybrid heterostructure devices $[67,68]$.

\section{Conclusions}

In this study, the $\mathrm{Au} / \mathrm{GO} / p$-InP heterojunction is fabricated and the electrical as well as photoelectrical properties are investigated. The ideality factor $(n)$ and the barrier height $\left(\Phi_{\mathrm{b}}\right)$ values of the $\mathrm{Au} / \mathrm{GO} / p$-InP heterojunction were found to be 1.67 and $0.87 \mathrm{eV}$ in the dark and 1.81 and $0.83 \mathrm{eV}$ in illumination conditions, respectively. The obtained $R_{\mathrm{S}}$ values from three distinct methods $(\log (I)-V$, Cheung's and Norde) exhibited a certain level of discrepancy, which could be possibly due to the fact that these methods were applied at different voltage regions of the $\log (I)-V$ data range. The $\Phi_{\mathrm{b}}$ and $n$ values deduced from $\Psi_{\text {surf }}-V$ plot are found to be $0.83 \mathrm{eV}, 1.82$ in the dark and $0.76 \mathrm{eV}, 1.78$ under illumination conditions, respectively. The interface state density is one order of magnitude lower for the $\mathrm{Au} / \mathrm{GO} / p$-InP heterojunction under illumination conditions compared to the same in dark conditions. The detailed analysis of $\log I-\log V$ characteristics elucidates that at lower voltage range (region I) the dominant conduction mechanism is ohmic-type behavior, whereas the behavior goes through the space-charge-limited-current (SCLC) conduction mechanism occupied at higher voltage range (i.e., region II and III) in dark and illuminated conditions. The results unveiled that the heterostructure performance in dark was substantially good compared to the same under the light (visible light) condition with respect to the lesser values of $I_{\mathrm{o}}, n, N_{\mathrm{ss}}$, and $R_{\mathrm{s}}$. The experimental consequences suggested that the $\mathrm{Au} / \mathrm{GO} / p-\mathrm{InP}$ heterostructure has promising characteristics to become an emerging candidate for the future photodiode applications.

Acknowledgements The authors would like to thank the National Science Fund for Excellent Young Scholars (51722509), National Key Research and Development Program of China (2017YFB1104700), Program for Science and Technology Innovation Group of Shaanxi Province (2019TD-011), and Key Research and Development Program of Shaanxi Province (2020ZDLGY04-02) for support..

Open Access This article is licensed under a Creative Commons Attribution 4.0 International License, which permits use, sharing, adaptation, distribution and reproduction in any medium or format, as long as you give appropriate credit to the original author(s) and the source, provide a link to the Creative Commons licence, and indicate if changes were made. The images or other third party material in this article are included in the article's Creative Commons licence, unless indicated otherwise in a credit line to the material. If material is not included in the article's Creative Commons licence and your intended use is not permitted by statutory regulation or exceeds the permitted use, you will need to obtain permission directly from the copyright holder. To view a copy of this licence, visit http://creativecommons.org/licenses/by/4.0/.

\section{References}

1. Horváth ZJ, Rakovics V, Szentpáli B, Püspöki S (2003) Schottky junctions on n-type InP for zero bias microwave detectors. Physica Status Solidi 3:916-921

2. Mccafferty PG, Sellai A, Dawson P, Elabd H (1996) Barrier characteristics of PtSip-Si Schottky diodes as determined from $I-V-\mathrm{T}$ measurements. Solid State Electron 39(4):583-592

3. Rhoderick EH, Rothwarf A (1979) Metal-semiconductor contacts. PHYS TODAY 32(5):66

4. Wilmsen CW (1985) Physics and chemistry of III-V compound semiconductor interfaces. Electrochim Acta 31(12):1680

5. Cova P, Singh A, Masut RA (1999) Simultaneous analysis of current-voltage and capacitance-voltage characteristics of metal-insulator-semiconductor diodes with a high mid-gap trap density. J Appl Phys 85(9):6530

6. Rajagopal Reddy V, Umapathi A, Dasaradha Rao L (2013) Effect of annealing on the electronic parameters of $\mathrm{Au} /$ poly(ethylmethacrylate)/n-InP Schottky diode with organic interlayer. Curr Appl Phys 13(8):1604-1610

7. Chen WX, Yuan MH, Wu K, Zhang YX, Wang ZM, Qin GG (1995) Experimental study on the Er/p-InP Schottky barrier. J Appl Phys 78(1):584-586586

8. Biber M, Co Kun C, Türüt A (2005) Current-voltage-temperature analysis of inhomogeneous $\mathrm{Au} / \mathrm{n}-\mathrm{GaAs}$ Schottky contacts. Eur Phys J Appl Phys 31(2):79-86

9. Lin Y, Huang J (2005) Mobility Enhancement and Breakdown Behavior in InP-Based Heterostructure Field-effect Transistor. J Electrochem Soc 152(8):G627. https://doi.org/10.1149/1.19380 08

10. Sugino T, Ito H (1990) Barrier height enhancement of InP Schottky junctions by treatment with photo-decomposed $\mathrm{PH} / \mathrm{sub}$ 3/. Electron Lett 26(21):1750-1751

11. Aydogan S, Saglam M, Tueruet A, Onganer Y (2009) Series resistance determination of $\mathrm{Au} /$ polypyrrole/ $p$-Si/Al structure by current-voltage measurements at low temperatures. Mater Sci Eng, C 29(4): 1486-1490

12. Güllü Türüt A (2008) Photovoltaic and electronic properties of quercetin/ $p$-InP solar cells. Sol Energy Mater Sol Cells 92(10): 1205-1210

13. Gu Llu O, Tu RuTA (2009) Electrical analysis of organic interlayer-based metal/interlayer/semiconductor diode structures. J Appl Phys 106(10):103716-103717

14. Aydin ME, Yakuphanoglu F, Eom JH, Hwang DH (2007) Electrical characterization of Al/MEH-PPV/p-Si Schottky diode by current-voltage and capacitance-voltage methods. Phys B 387(1-2):239-244

15. Kilicoglu T, Tombak A, Ocak YS, Aydemir M (2014) Electrical and photoelectrical characterization of a TTF/ $p$-InP organicinorganic heterojunction. Microelectron Eng 129:91-95

16. Lin S, Peng W, Li X, Wu Z, Xu Z, Zhang S, Xu W (2015) Gate tunable monolayer MoS2/InP heterostructure solar cells. Appl Phys Lett 9 (7):666

17. Chen J, Wang Q, Lv J (2016) Electronic properties of Al/ $\mathrm{MoO}_{3} / p$-InP enhanced Schottky barrier contacts. Thin Solid Films 616:145-150

18. Reddy M, Sreenu K, Reddy V, Park C (2017) Modified electrical properties and transport mechanism of Ti/p-InP Schottky structure with a polyvinylpyrrolidone (PVP) polymer interlayer. J Mater Sci Mater Electron 28(6):4847-4855

19. Padma R, Sreenu K, Reddy V (2017) Electrical and frequency dependence characteristics of Ti/polyethylene oxide (PEO)/ptype InP organic-inorganic Schottky junction. J Alloy Compd 695:2587-2596 
20. Sreenu K, Venkata Prasad C, Rajagopal Reddy V (2017) Barrier parameters and current transport characteristicsof Ti/ $p$-Inp schottky junction modified using orange $\mathrm{G}(\mathrm{OG})$ organic interlayer. J Electron Mater 46:5746-5754

21. Acar FZ, Buyukbas-Ulusan A, Tataroglu A (2018) Analysis of interface states in $\mathrm{Au} / \mathrm{ZnO} / p$-InP (MOS) structure. J Mater Sci: Mater Electron 29(15):12553-12560

22. Aydin H, Bacaksiz C, Yagmurcukardes N, Karakaya C, Mermer O, Can M, Senger RT, Sahin H, Selamet Y (2018) Experimental and computational investigation of graphene/SAMs/n-Si Schottky diodes. Appl Surf Sci 428:1010-1017

23. Tomer D, Rajput S, Hudy LJ, Li CH, Li L (2015) Inhomogeneity in barrier height at graphene/Si (GaAs) Schottky junctions. Nanotechnology 26(21):215702

24. Shivaraman S (2012) Schottky barrier inhomogeneities at the interface of few layer epitaxial graphene and silicon carbide. Appl Phys Lett 100(18):1-4

25. Giannazzo F, Raineri V, Yakimova R, Huntzinger JR, Tiberj A, Camassel J, Sonde S (2009) Electrical properties of the graphene/4 H -SiC (0001) interface probed by scanning current spectroscopy. Phys Rev B 80(24):241406. https://doi.org/10.1103/ PhysRevB.80.241406

26. Park PS, Reddy KM, Nath DN, Yang Z, Padture NP, Rajan S (2013) Ohmic contact formation between metal and AlGaN/ $\mathrm{GaN}$ heterostructure via graphene insertion. Appl Phys Lett 102(15):1535011-1535014

27. Fisichella G, Greco G, Roccaforte F, Giannazzo F (2014) From Schottky to Ohmic graphene contacts to $\mathrm{AlGaN} / \mathrm{GaN}$ heterostructures: role of the AlGaN layer microstructure. Appl Phys Lett 105(6):63111-63117

28. Tongay S, Lemaitre M, Schumann T, Berke K, Appleton BR, Gila B, Hebard AF (2011) Graphene/GaN Schottky diodes: stability at elevated temperatures. Appl Phys Lett 99(10):102101-102102

29. Zhong H, Liu Z, Shi L, Xu G, Fan Y, Huang Z, Wang J, Ren G, Xu $\mathrm{K}$ (2014) Graphene in ohmic contact for both n-GaN and p-GaN. Appl Phys Lett 104(21):212101

30. Kim S, Lee JM, Dong HL, Park WI (2013) The effect of thermal annealing of graphene under ammonia atmosphere on its electrical properties and contact to p-GaN. Thin Solid Films 546(1):246-249

31. Shiu Hung W, Lo YC, Kai-Hsuan L, Chen H-Y (2013) Graphene as tunable transparent electrode material on GaN: layer-number-dependent optical and electrical properties. Appl Phys Lett 103(8):1-4

32. Khurelbaatar Z, Kil YH, Yun HJ, Shim KH, Nam JT, Kim KS, Lee SK, Choi CJ (2014) Modification of Schottky barrier properties of $\mathrm{Au} / \mathrm{n}$-type Ge Schottky barrier diode using monolayer graphene interlayer. J Alloy Compd 614:323-329

33. Khurelbaatar Z, Kang M, Shim K, Yun H, Lee J, Hong H, Chang S, Lee S, Choi C (2015) Temperature dependent current-voltage characteristics of Au/n-type Ge Schottky barrier diodes with graphene interlayer. J Alloy Compd 650:658-663. https://doi. org/10.1016/j.jallcom.2015.08.031

34. Kalita G, Hirano R, Ayhan ME, Tanemura M (2013) Fabrication of Schottky junction diode with direct growth graphene on silicon by a solid phase reaction. J Phys D Appl Phys 46(45):5326-5333

35. Wang X, Wang Y, Li D, Zou L, Zhang Q, Zhou J, Liu D, Zhang Z (2015) Thermal annealing and air exposing effect on the graphene/ silicon Schottky junctions. Solid State Commun 201:115-119. https://doi.org/10.1016/j.ssc.2014.10.028

36. Lin Y (2015) Correlation between phonon and impurity scatterings, potential fluctuations and leakage conduction of graphene/ntype Si Schottky diodes. Superlattice Microst 88:645-650. https ://doi.org/10.1016/j.spmi.2015.10.031
37. Chen C, Aykol M, Chang C, Levi AFJ, Cronin SB (2011) Graphene-silicon Schottky diodes. Nano Lett 11(5):1863-1867. https ://doi.org/10.1021/nl104364c

38. Mohammed M, Li Z, Cui J, Chen T (2012) Junction investigation of graphene/silicon Schottky diodes. Nanoscale Res Lett 7(1):302. https://doi.org/10.1186/1556-276x-7-302

39. Zeng J, Lin Y (2014) Schottky barrier inhomogeneity for graphene/Si-nanowire arrays/n-type Si Schottky diodes. Appl Phys Lett 104(13):133506. https://doi.org/10.1063/1.4870258

40. Niu G, Capellini G, Hatami F, Di Bartolomeo A, Niermann T, Hussein EH, Schubert MA, Krause H, Zaumseil P, Skibitzki O, Lupina G, Masselink WT, Lehmann M, Xie Y, Schroeder $\mathrm{T}$ (2016) Selective Epitaxy of InP on Si and Rectification in Graphene/InP/Si Hybrid Structure. ACS Appl Mater Inter 8(40):26948-26955. https://doi.org/10.1021/acsami.6b09592

41. Wang P, Li X, Xu Z, Wu Z, Zhang S, Xu W, Zhong H, Chen H, Li E, Luo J, Yu Q, Lin S (2015) Tunable graphene/indium phosphide heterostructure solar cells. Nano Energy 13:509-517. https://doi.org/10.1016/j.nanoen.2015.03.023

42. Gullu O, Cankaya M, Rajagopal Reddy V (2019) Barrier enhancement of $\mathrm{Al} / \mathrm{n}$-InP Schottky diodes by graphene oxide thin layer. Indian J Phys 93(4):467-474. https://doi.org/10.1007/ s12648-018-1311-4

43. Phan DT, Gupta RK, Chung GS, Al-Ghamdi AA, Al-Hartomy OA, El-Tantawy F, Yakuphanoglu F (2012) Photodiodes based on graphene oxide-silicon junctions. Sol Energy 86(10):29612966. https://doi.org/10.1016/j.solener.2012.07.002

44. Kalita G, Wakita K, Umeno M, Tanemura M (2013) Fabrication and characteristics of solution-processed graphene oxide-silicon heterojunction. Physica Status Solidi 7(5):340-343. https ://doi.org/10.1002/pssr.201206516

45. Yang L, Yu X, Xu M, Chen H, Yang D (2014) Interface engineering for efficient and stable chemical-doping-free grapheneon-silicon solar cells by introducing a graphene oxide interlayer. J Mater Chem A 2(40):16877-16883. https://doi.org/10.1039/ C4TA02216E

46. Sze S (1981) Physics of semiconductor devices. New York. Serbiula (sistema Librum 2.0) 1. https://doi.org/10.1063/1.30222 05

47. Dahlan AS, Tataroğlu A, Al-Ghamdi AA, Al-Ghamdi AA, BinOmran S, Al-Turki Y, El-Tantawy F, Yakuphanoglu F (2015) Photodiode and photocapacitor properties of $\mathrm{Au} / \mathrm{CdTe} / \mathrm{p}-\mathrm{Si} / \mathrm{Al}$ device. J Alloy Compd 646:1151-1156. https://doi.org/10.1016/j. jallcom.2015.06.068

48. Sands T (1988) Stability and epitaxy of NiAl and related intermetallic films on III-V compound semiconductors. Appl Phys Lett 52(3):197-199. https://doi.org/10.1063/1.99518

49. Şahin B, Çetin H, Ayyildiz E (2005) The effect of series resistance on capacitance-voltage characteristics of Schottky barrier diodes. Solid State Commun 135(8):490-495. https://doi.org/10.1016/j. ssc. 2005.05 .050

50. Tung RT, Sullivan JP, Schrey F (1992) On the inhomogeneity of Schottky barriers. Mater Sci Eng, B 14(3):266-280. https://doi. org/10.1016/0921-5107(92)90309-W

51. Greco G, Prystawko P, Leszczyński M, Lo Nigro R, Raineri V, Roccaforte F (2011) Electro-structural evolution and Schottky barrier height in annealed $\mathrm{Au} / \mathrm{Ni}$ contacts onto p-GaN. J Appl Phys 110(12):123703. https://doi.org/10.1063/1.3669407

52. Cheung SK, Cheung NW (1986) Extraction of Schottky diode parameters from forward current-voltage characteristics. Appl Phys Lett 49(2):85-87. https://doi.org/10.1063/1.97359

53. Norde H (1979) A modified forward $I-V$ plot for Schottky diodes with high series resistance. J Appl Phys 50(7):5052-5053. https ://doi.org/10.1063/1.325607 
54. Chattopadhyay P (1995) A new technique for the determination of barrier height of Schottky barrier diodes. Solid State Electron 38(3):739-741. https://doi.org/10.1016/0038-1101(94)00167-E

55. Aydoğan S, Sağlam M, Türüt A (2005) Current-voltage and capacitance-voltage characteristics of polypyrrole/ $p$-InP structure. Vacuum 77(3):269-274. https://doi.org/10.1016/j.vacuu m.2004.10.003

56. Chattopadhyay S, Bera LK, Ray SK, Bose PK, Maiti CK (1998) Extraction of interface state density of Pt/p-strained-Si Schottky diode. Thin Solid Films 335(1):142-145. https://doi.org/10.1016/ S0040-6090(98)00892-X

57. Siad M, Keffous A, Mamma S, Belkacem Y, Menari H (2004) Correlation between series resistance and parameters of $\mathrm{Al} / \mathrm{n}-\mathrm{Si}$ and Al/p-Si Schottky barrier diodes. Appl Surf Sci 236(1):366376. https://doi.org/10.1016/j.apsusc.2004.05.009

58. Soylu M, Yakuphanoglu F (2010) Analysis of barrier height inhomogeneity in Au/n-GaAs Schottky barrier diodes by Tung model. J Alloy Compd 506(1):418-422. https://doi.org/10.1016/j.jallc om.2010.07.019

59. Card HC, Rhoderick EH (1971) Studies of tunnel MOS diodes I@@ Interface effects in silicon Schottky diodes. J Phys D Appl Phys 4(10):1589-1601. https://doi. org/10.1088/0022-3727/4/10/319

60. Taşçı̆̆ğlu I, Soylu M, Altındal S, Al-Ghamdi AA, Yakuphanoglu F (2012) Effects of interface states and series resistance on electrical properties of $\mathrm{Al} / \mathrm{nanostructure} \mathrm{CdO} / \mathrm{p}-\mathrm{GaAs}$ diode. J Alloy Compd 541:462-467. https://doi.org/10.1016/j.jallc om.2012.07.001

61. Güllü Ö, Aydoğan S, Türüt A (2008) Fabrication and electrical characteristics of Schottky diode based on organic material. Microelectron Eng 85(7):1647-1651. https://doi.org/10.1016/j. mee.2008.04.003

62. Card HC, Rhoderick EH (1971) Studies of tunnel MOS diodes II@ Thermal equilibrium considerations. J Phys D Appl Phys 4(10):1602-1611. https://doi.org/10.1088/0022-3727/4/10/320

63. Uslu H, Altındal S, Aydemir U, Dökme I, Afandiyeva IM (2010) The interface states and series resistance effects on the forward and reverse bias $I-V, C-V$ and $G / \omega-V$ characteristics of Al-TiWPd2Si/n-Si Schottky barrier diodes. J Alloy Compd 503(1):96102. https://doi.org/10.1016/j.jallcom.2010.04.210

64. Aydoğan S, İncekara Ü, Deniz AR, Türüt A (2010) Extraction of electronic parameters of Schottky diode based on an organic Orcein. Microelectron Eng 87(12):2525-2530. https://doi. org/10.1016/j.mee.2010.06.004

65. Dutta M, Basak D (2008) p-ZnO/n-Si heterojunction: sol-gel fabrication, photoresponse properties, and transport mechanism. Appl Phys Lett 92(21):212112. https://doi.org/10.1063/1.2937124

66. El-Sayed SM, Abdel Hamid HM, Radwan RM (2004) Effect of electron beam irradiation on the conduction phenomena of unplasticized PVC/PVA copolymer. Radiat Phys Chem 69(4):339-345. https://doi.org/10.1016/j.radphyschem.2003.07.001

67. Gupta RK, Yakuphanoglu F, Hasar H, Al-Khedhairy AA (2011) p-Si/DNA photoconductive diode for optical sensor applications. Synthetic Met 161(17):2011-2016. https://doi.org/10.1016/j.synth met.2011.07.016

68. Demirezen S, Altındal S, Uslu I (2013) Two diodes model and illumination effect on the forward and reverse bias $I-V$ and $C-V$ characteristics of Au/PVA (Bi-doped)/n-Si photodiode at room temperature. Curr Appl Phys 13(1):53-59. https://doi. org/10.1016/j.cap.2012.06.009

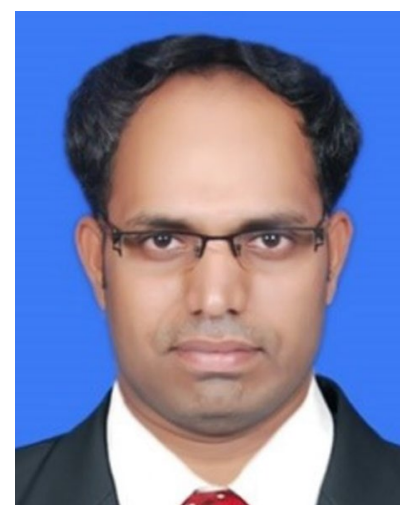

Dasaradha Rao Lambada received his PhD degree in Physics from Sri Venkateswara University. His research interest includes fabrication of novel Schottky and ohmic contacts for single-crystalline and compound semiconductors, polymer-based Schottky contacts to wide band gap Semiconductors, and surface analysis of III-V and II-VI semiconductors.

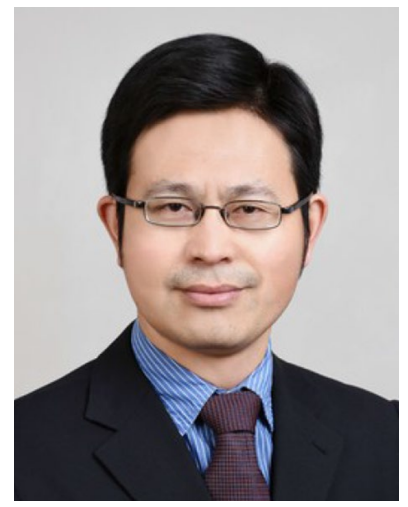

Shuming Yang is currently a full professor at School of Mechanical Engineering, Xi'an Jiaotong University (XJTU), China. He achieved his BSc and MSc in mechanical engineering from XJTU, and Ph.D. in nanotechnology and instrumentation from University of Huddersfield $(\mathrm{UoH})$ of the UK. He then started to work at $\mathrm{UoH}$, after that he joined in XJTU till now. His research areas include micro-/ nano-fabrication and measurement, optical technology and instrumentation, precision/ultraprecision manufacturing etc. He has held more than 20 research projects including National Key R\&D Program of China, National Science and Technology Major Projects etc. He has published more than 130 academic papers and owned 60 patents of PCT, UK, European and China. He achieved the first class of Science and Technology Progress Award from the Ministry of Education, the first class of Machinery Industry Science and Technology Award of China, the first class of Shaanxi Science and Technology Award, and the second class of Science and Technology Progress Award from the Chinese Society for measurement (CSM) etc. He was elected as a fellow of the International Society for Nanomanufacturing (ISNM). He is also an associate editor of Journal of Manufacturing Systems, an editor of Nanomanufacturing and Nanometrology, a guest editor of Measurement Science and Technology, and a guest editor of the International Journal of Advanced Manufacturing Technology etc.

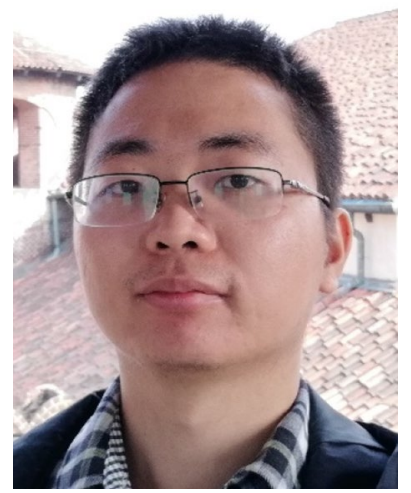

Yiming Wang is presently a $\mathrm{PhD}$ candidate at State Key Laboratory for Manufacturing Systems Engineering in School of Mechanical Engineering of Xi'an Jiaotong University, Xi' an, China. He received his $\mathrm{BSc}$ degree from Xi' an Jiaotong University in 2014. His current research interests include graphene synthesis and graphene photodetector. 


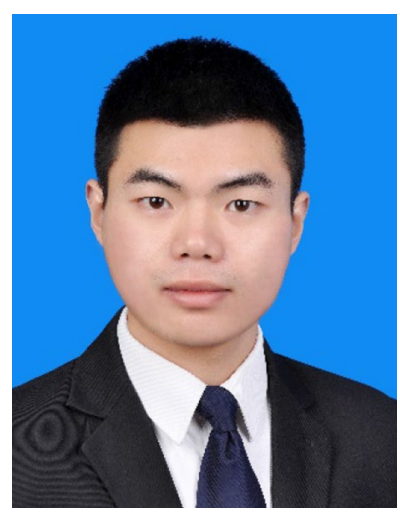

Peirui Ji is currently a Ph.D. candidate at the School of Mechanical Engineering, Xi' an Jiaotong University. He received his bachelor's degree from Xi' an Jiaotong University in 2017. His research interests include integrated optics, graphene optoelectronic device.

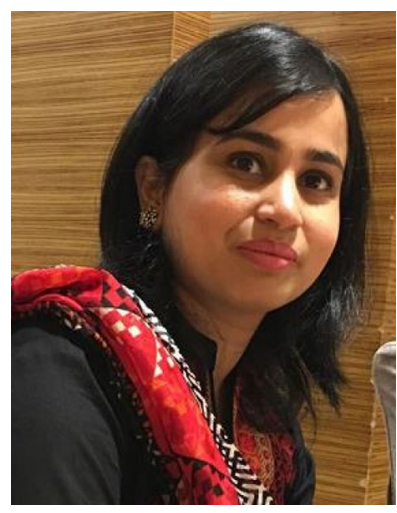

Shareen Shafique received her University, Xi' an, China, and her MS degree from University of the Punjab, Lahore, Pakistan. Her research interest includes synthesis of nanostructured materials for the photodetectors applications. $\mathrm{PhD}$ degree from Xi' an Jiaotong

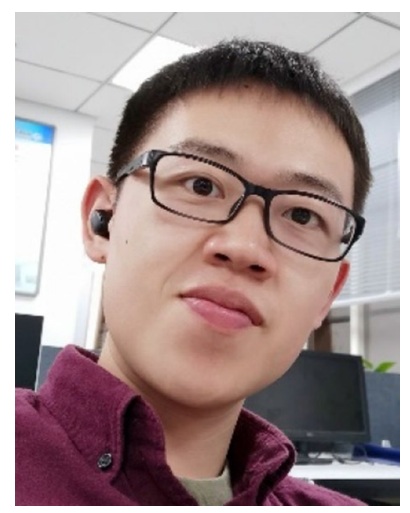

Fei Wang is presently a $\mathrm{PhD}$ candidate at State Key Laboratory for Manufacturing Systems Engineering in School of Mechanical Engineering of Xi' an Jiaotong University, Xi'an, China. He received his BSc degree from Dalian University of Technology in 2014. His current research interests include Scanning near-field optical microscope and nano-surface property detection. 